\title{
Dexmedetomidine Infusion an Effective Intra-Operative Medication for Patients Undergoing Laparoscopic Cholecystectomy
}

\author{
Summaira Jan ${ }^{1}$, Tawheed Ahmad ${ }^{2 *}$ and Saima Rashid ${ }^{3}$ \\ ${ }^{1}$ Department of Anaesthesia, SKIMS, India \\ ${ }^{2}$ Department of Surgery, KAAUH, Princess Nourah University, Saudi Arabia \\ ${ }^{3}$ Department of Anatomy, GMC, India
}

*Corresponding author: Dr. Tawheed Ahmad, Assistant Professor, Department of Surgery, KAAUH, Princess Nourah University, Saudi Arabia

\begin{abstract}
Background: Laparoscopic surgeries involves creation of pneumo-peritoneum with insufflation of gas usually $\mathrm{CO}_{2}$ thereby increasing intra-abdominal pressure. The Intra-abdominal pressure above $10 \mathrm{mmHg}$ causes adverse hemodynamic changes. Various agents have been used to attenuate these adverse effects. Dexmedetomidine alpha-2 agonist has sedative, sympatholytic, analgesic and anxiolytic properties and used in laparoscopic cholecystectomies for attenuation of adverse hemodynamic changes and to maintain hemodynamic stability.
\end{abstract}

Material and methods: 60 patients of ASA 1-2 undergoing elective laparoscopic cholecystectomy were randomly allotted to two groups. Each group consists of 30 patients. Group 1 patients received dexmedetomidine infusion @0.2 microgram $/ \mathrm{kg} /$ hour and group 2 patients received normal saline @0.2 microgram $/ \mathrm{kg} /$ hour after intubation. The medication was stopped at the end of peritoneal deflation. Intraoperative hemodynamic stability was assessed by monitoring heart rate and Mean arterial pressure.

Results: In Dexmedetomidine group, the haemodynamic response was significantly attenuated.

Conclusion: Dexmedetomidine infusion in the dose of 0.2 $\mu \mathrm{g} / \mathrm{kg} /$ hour effectively attenuates haemodynamic stress response to pneumo-peritoneum during laparoscopic surgery.

\section{Keywords}

Dexmedetomidine, Laparoscopic Cholecystectomy

\section{Introduction}

Laparoscopic surgery is a modern surgical technique involving insufflation of gas (usually $\mathrm{CO}_{2}$ ) into the peri- toneal cavity, under pressure, to separate the organs within the abdominal cavity [1]. Because of its minimal scar, less postoperative pain, decreased length of hospital stay and obviously less mortality, it has become the gold standard for treatment of gall bladder diseases [2]. Laparoscopic cholecystectomy is one of the most commonly undertaken procedures in general surgery, with overall complication rate being less than $1.5 \%$ and the overall mortality rate of less than $0.1 \%$ [3]. However pneumoperitoneum (PNP) required for this procedure affects several systems leading to alterations in cardiovascular, respiratory, stress response and acid-base physiology. The nature of changes in cardiovascular system associated with pneumoperitoneum includes an increase in mean arterial pressure, decrease in cardiac output and increase in systemic vascular resistance which can lead to altered tissue perfusion. These changes though better tolerated in ASA I and II patients can be detrimental in elderly and ASA III patients particularly with compromised cardiovascular system physiology. Various surgical methods like change in nature of insufflating gas, [4] use of low intra-abdominal pressure [5,6], use of abdominal wall lift methods [7] have been tried to decrease the hemodynamic alterations seen with pneumoperitoneum, but all with practical limitations. Various anesthetic interventions like use of epidural, segmental spinal [8], combined epidural and general anaesthesia [9], use of various pharmacologic interventions like nitroglycerine [10], esmolol [11], magnesium sulphate [12] have been used with varying

Citation: Jan S, Ahmad T, Rashid S (2018) Dexmedetomidine Infusion an Effective Intra-Operative Medication for Patients Undergoing Laparoscopic Cholecystectomy. Int J Anesthetic Anesthesiol 5:083. doi.org/10.23937/2377-4630/1410083

Accepted: December 18, 2018: Published: December 20, 2018

Copyright: (C) 2018 Jan S, et al. This is an open-access article distributed under the terms of the Creative Commons Attribution License, which permits unrestricted use, distribution, and reproduction in any medium, provided the original author and source are credited. 
success and practical limitations. Aho, et al. [13] used alpha 2 adrenergic receptor agonist for prevention of hemodynamic responses associated with laparoscopic surgery. They found that dexmedetomidine effectively reduces the maximum heart rate response after intubation and pneumoperitoneum. As laparoscopic cholecystectomy is a routinely performed surgery, it is desirable to have a stable intraoperative haemodynamic status. Hence in this study, it has been attempted to study the beneficial effect of $\alpha-2$ adrenergic agonist dexmedetomidine in maintaining the perioperative parameters during laparoscopic cholecystectomy.

\section{Materials and Methods}

The present study was carried out in 60 patients of ASA Grade I and II between the age group of 20$60 y$ rs of both genders scheduled to undergo elective laparoscopic cholecystectomy. They were randomly divided into two groups of 30 patients each. Group I $(n=$ 30): Dexmedetomidine group- $200 \mathrm{mcg}(2 \mathrm{ml})$ in $38 \mathrm{ml}$ of $0.9 \%$ NS @ $0.2 \mu \mathrm{g} / \mathrm{kg} / \mathrm{hr}$ infusion was given. Group II (n $=50)$ : Control group $-0.9 \%$ saline was given at same rate.

Exclusion criteria: Patients with chronic hypertension, ASA physical status III, AV block, morbid obesity (> $50 \%$ above ideal body weight), acute cholecystitis, chronic use of opioid analgesics or $\beta$-blockers, asthma or reactive airway disease and those with severe renal, hepatic, endocrine and cardiac dysfunction was excluded from the study. A thorough pre-anesthetic evaluation was done a day prior to surgery and all the necessary investigations were carried out including specific investigations if required. A written informed consent was taken from every patient. All the patients were kept fasting overnight and were given tablet ranitidine $150 \mathrm{mg}$ a night before surgery. On arrival to operation theatre, intravenous (IV) line was secured and crystalloid intravenous infusion of $6-8 \mathrm{ml} / \mathrm{kg} / \mathrm{hr}$ was started. Routine monitoring like ECG, NIBP and pulse oximetry was started and baseline parameters were recorded. All patients were premedicated with IV Injection midazolam 1-2 mg and Glycopyrrolate $0.02 \mathrm{mg} / \mathrm{kg}$. After preoxygenation for 3 minutes with $100 \%$ oxygen, general anaesthesia was induced with inj. propofol $2 \mathrm{mg} / \mathrm{kg}, \mathrm{O}_{2}$ and $\mathrm{N}_{2} \mathrm{O}$. Analgesia was given using Fentanyl 2 microgram $/ \mathrm{kg}$. After preoxygenation, endotracheal intubation was facilitated by muscle relaxant Atracurium $0.5 \mathrm{mg} / \mathrm{kg}$. Group I patients were given dexmedetomidine by IV infusion @0.2 $\mu \mathrm{g} / \mathrm{kg} /$ $\mathrm{hr}$ intraoperatively after tracheal intubation. This drug was prepared in identical $50 \mathrm{ml}$ syringe by adding Dexmedetomidine $200 \mu \mathrm{g}(2 \mathrm{ml})$ in $0.9 \%$ saline $(38 \mathrm{ml})$ making a total volume of $40 \mathrm{ml}$ (resulting concentration will be $5 \mu \mathrm{g} / \mathrm{ml}$ ). Group II patients were given $0.9 \%$ saline at the same rate. Anesthesia was maintained with $\mathrm{O}_{2}: \mathrm{N}_{2} \mathrm{O}$ (50:50), isoflurane, IPPV. Supplemental neuromuscular blockade was achieved with Atracurium $0.1 \mathrm{mg} / \mathrm{kg}$. Endtidal carbon dioxide $\left(\mathrm{EtCO}_{2}\right)$ was maintained between $35-40 \mathrm{mmHg}$. Pneumoperitoneum was created and Intra-abdominal pressure was maintained between $12-14 \mathrm{mmHg}$ throughout the laparoscopic procedure. Intraoperatively patients were monitored for NIBP and heart rate at every $5 \mathrm{~min}$ interval. Hypotension defined as NIBP $<20 \%$ of the baseline or systolic BP $<90 \mathrm{mmHg}$ was treated by increasing the intravenous crystalloid infusion rate and additionally with vasoactive drugs. Bradycardia, defined as heart rate $<20 \%$ of the baseline or less than 50 beats/min, was treated with $0.02 \mathrm{mg} /$ $\mathrm{kg}$ atropine. After the release of pneumoperitoneum, infusion of the drug was stopped. Injection ondansetron $4 \mathrm{mg}$ was given before reversal of neuromuscular blockade by neostigmine $0.05 \mathrm{mg} / \mathrm{kg}$ and Glycopyrrolate $0.02 \mathrm{mg} / \mathrm{kg}$ and patient was extubated. After extubation, time to response to verbal commands was recorded. Post-operatively $100 \%$ oxygen was given by face mask for 15 minutes. The results obtained in the study are presented in tabulated manner. Statistical analysis was done using student's t-test and Chi square test was performed for nonparametric values. $P$ value $<0.05$ was considered statistically significant.

\section{Observations and Results}

Two groups were comparable with respect to age, gender, weight and duration of surgery (Table 1). There was no significant difference in preoperative values between the two groups (Table 2). After 5 minutes of dexmedetomidine infusion, mean arterial pressure (MAP) and heart rate decreased significantly in group

Table 1: Patient characteristics and duration of surgery.

\begin{tabular}{|c|c|c|c|c|}
\hline & Group 1 & Group 2 & $P$ value & Statistical significance \\
\hline Age (years) & $35.4 \pm 11.1$ & $36.6 \pm 10.5$ & $>0.05$ & NON-Significant \\
\hline Gender (M/F) & $22 / 24$ & $23 / 27$ & $>0.05$ & NON-Significant \\
\hline Weight & $57.8 \pm 8$ & $58.8 \pm 8.7$ & $>0.05$ & NON-Significant \\
\hline Duration of surgery & $52.25 \pm 3.81$ & $50.20 \pm 10.87$ & $>0.05$ & NON-Significant \\
\hline
\end{tabular}

Table 2: Pre-operative vitals in Group I and Group II.

\begin{tabular}{|c|c|c|c|c|c|c|}
\hline \multirow[b]{2}{*}{ Parameters } & \multicolumn{2}{|c|}{ Group 1} & \multicolumn{2}{|c|}{ Group 2} & \multirow[b]{2}{*}{$P$ value } & \multirow[b]{2}{*}{ Statistical Significance } \\
\hline & Mean & SD & Mean & SD & & \\
\hline $\mathrm{HR} / \mathrm{min}$ & 83.86 & 9.15 & 84.60 & 7.12 & 0.58 & NS \\
\hline SBP & 122.82 & 10.74 & 120.74 & 8.67 & 0.27 & NS \\
\hline DBP & 78.54 & 5.92 & 76.44 & 4.98 & 0.12 & NS \\
\hline MBP & 93.73 & 6.11 & 91.63 & 5.22 & 0.09 & NS \\
\hline
\end{tabular}


Table 3: Changes in HR at different time interval in Group I and Group II.

\begin{tabular}{|c|c|c|c|c|c|c|}
\hline Group & Gro & & Grc & & & \\
\hline Time interval & $\mathrm{N}$ & Mean \pm SD & $\mathrm{N}$ & Mean \pm SD & $p$-value & Statistical Significance \\
\hline Preoperative & 50 & $83 \pm 9.3$ & 50 & $84.5 \pm 6.6$ & 0.67 & NS \\
\hline Postintubation & 50 & $110 \pm 8.76$ & 50 & $107.8 \pm 8.45$ & 0.08 & NS \\
\hline Post pneumoperitoneum M 5 & 50 & $83.2 \pm 12.0$ & 50 & $102 \pm 10.5$ & 0.00 & S \\
\hline M10 & 50 & $83.2 \pm 12.1$ & 50 & $101.5 \pm 11.8$ & 0.00 & S \\
\hline M15 & 50 & $84.8 \pm 11.2$ & 50 & $103.3 \pm 10.6$ & 0.00 & S \\
\hline M20 & 50 & $83.2 \pm 10.5$ & 50 & $98.8 \pm 11.7$ & 0.00 & S \\
\hline M25 & 50 & $80.6 \pm 11.5$ & 50 & $94.7 \pm 10.4$ & 0.00 & S \\
\hline M35 & 50 & $81.9 \pm 11.0$ & 50 & $96.5 \pm 11.7$ & 0.00 & S \\
\hline M40 & 50 & $82.2 \pm 11.5$ & 50 & $92.2 \pm 11.5$ & 0.00 & S \\
\hline M45 & 50 & $81.6 \pm 10.8$ & 50 & $94.8 \pm 11.1$ & 0.00 & $S$ \\
\hline M50 & 50 & $82.2 \pm 10.9$ & 50 & $95.4 \pm 11.3$ & 0.00 & S \\
\hline M55 & 50 & $81.5 \pm 10.8$ & 50 & $91.4 \pm 9.3$ & 0.00 & S \\
\hline M60 & 50 & $82.4 \pm 9.5$ & 50 & $92.7 \pm 10.7$ & 0.00 & S \\
\hline M65 & 50 & $81.8 \pm 10.6$ & 50 & $101.5 \pm 11.6$ & 0.00 & $S$ \\
\hline Post deflation & 50 & $84 \pm 10.7$ & 50 & $103.3 \pm 10.6$ & 0.00 & $S$ \\
\hline Post extubation & 50 & $82.0 \pm 11.7$ & 50 & $101.6 \pm 10.7$ & 0.00 & $S$ \\
\hline
\end{tabular}

Table 4: Changes in MBP at different time interval in Group I and Group II.

\begin{tabular}{|l|l|l|l|l|l|l|}
\hline Group & \multicolumn{3}{l}{ Group 1 } & \multicolumn{2}{l|}{ Group 2 } & \\
\hline Time interval & $\mathrm{N}$ & Mean \pm SD & $\mathrm{N}$ & Mean \pm SD & p-value & Statistical Significance \\
\hline Preoperative & 50 & $93.7 \pm 6.5$ & 50 & $91.7 \pm 7.4$ & 0.12 & NS \\
\hline Postintubation & 50 & $102.02 \pm 7.5$ & 50 & $99.55 \pm 8.0$ & 0.07 & NS \\
\hline Post pneumoperitoneum M5 & 50 & $87.5 \pm 8.5$ & 50 & $100.6 \pm 10.4$ & 0.00 & S \\
\hline M10 & 50 & $89.5 \pm 8.0$ & 50 & $101.1 \pm 11.2$ & 0.00 & S \\
\hline M15 & 50 & $86.8 \pm 8.7$ & 50 & $100.4 \pm 10.5$ & 0.00 & S \\
\hline M20 & 50 & $84.0 \pm 7.3$ & 50 & $100.5 \pm 9.6$ & 0.00 & S \\
\hline M25 & 50 & $88.5 \pm 7.4$ & 50 & $97.5 \pm 8.1$ & 0.00 & S \\
\hline M35 & 50 & $85.7 \pm 6.7$ & 50 & $98.7 \pm 12.0$ & 0.00 & S \\
\hline M40 & 50 & $87.5 \pm 5.5$ & 50 & $94.5 \pm 9.5$ & 0.00 & S \\
\hline M45 & 50 & $88.0 \pm 9.1$ & 50 & $97.6 \pm 11.7$ & 0.00 & S \\
\hline M50 & 50 & $86.0 \pm 9.3$ & 50 & $94.7 \pm 7.1$ & 0.00 & S \\
\hline M55 & 50 & $87.7 \pm 7.3$ & 50 & $95.2 \pm 9.5$ & 0.00 & S \\
\hline M60 & 50 & $85.8 \pm 7.2$ & 50 & $96.4 \pm 12.6$ & 0.00 & S \\
\hline M65 & 50 & $84.2 \pm 8.56$ & 50 & $95.7 \pm 9.5$ & 0.00 & S \\
\hline Post deflation & 50 & $90.67 \pm 7.67$ & 50 & $102.56 \pm 11.6$ & 0.00 & S \\
\hline Post extubation & 50 & $88.6 \pm 8.54$ & 50 & $101.54 \pm 10.55$ & 0.00 & S \\
\hline
\end{tabular}

I than in group II $(P<0.05)$. MAP and heart rate was significantly lower $(P<0.05)$ during pneumoperitoneum, remained lower throughout the surgery and in postoperative period in group I as compared to group II (Table 3 and Table 4).

\section{Discussion}

Laparoscopic cholecystectomy is one of the routine procedures done in general surgery. However pneumoperitoneum and positioning required for this procedure alters the cardiovascular, respiratory, neuroendocrine and acid base physiology. $\alpha-2$ adrenoceptor agonists are now being frequently used in anesthesia as they decrease sympathetic tone and attenuate the stress responses to intubation and surgery. Infusion doses of dexmedetomidine varying from 0.1 to $10 \mu \mathrm{g} / \mathrm{kg} / \mathrm{h}[14,15]$ have been studied. Even the low dose infusion of $0.25-0.5 \mu \mathrm{g} / \mathrm{kg} / \mathrm{h}$ are effective in blunting stress response and decrease in systemic catecholamines [16]. In our study dose of
$0.2 \mu \mathrm{g} / \mathrm{kg} / \mathrm{hr}$ infusion had significant hemodynamic stability during intra and post-operative period. It is an effective alternative to benzodiazepine and opioids in patients undergoing monitored anaesthesia care because of its analgesic, arousal sedation and lack of respiratory depression properties [17]. $\alpha-2$ adrenoceptors are found in many sites in the central nervous system, highest densities in the locus ceruleus, the predominant noradrenergic nuclei of the brainstem which contributes to the maintenance of arousal or wakefulness. Presynaptic activation of the $\alpha-2$ adrenoceptor in the locus ceruleus inhibits the release of norepinephrine and results in the sedative and hypnotic effects. Dexmedetomidine infusion also enables smooth extubation without causing hemodynamic instability, undue sedation and maintains plasma noradrenaline concentration [18]. Dexmedetomidine in a dose of $0.2 \mu \mathrm{g} / \mathrm{kg} / \mathrm{hr}$ is effective in blunting stress response to pneumoperitoneum [19]. Bhattacharjee DP, et al. [20] showed the effects of Dexmedetomidine 
infusion $(0.2 \mu \mathrm{g} / \mathrm{kg} / \mathrm{hour})$ for hemodynamic stability in patients undergoing laparoscopic cholecystectomy and found that heart rate in Dexmedetomidine group was significantly less after intubation and throughout the period of pneumoperitoneum [20]. In our study the mean heart rate was also significantly lower in dexmedetomidine group.

\section{Conclusion}

Low dose infusion of dexmedetomidine at the rate of $0.2 \mu \mathrm{g} / \mathrm{kg} / \mathrm{hr}$ serves as a very useful anaesthesia adjuvant to control hemodynamic stress response to pneumoperitoneum and extubation in patients undergoing laparoscopic cholecystectomy.

\section{References}

1. Dubois F, Icard P, Berthelot G, Levard H (1990) Coelioscopic cholecystectomy. Preliminary report of 36 cases. Ann Surg 211: 60-62.

2. (1993) NIH Consensus conference. Gall stones and laparoscopic cholecystectomy. JAMA 269: 1018-1024.

3. Osborne DA, Alexander G, Boe B, Zervos EE (2006) Laparoscopic cholecystectomy: Past, present and future. Surg Technol Int 15: 81-85.

4. Menes T, Spivak H (2000) Laparoscopy: Searching for the proper insufflation gas. Surg Endosc 14: 1050-1056.

5. Dexter SPL, Vucevic M, Gibson J, McMahon MJ (1999) Hemodynamic consequences of high- and low-pressure capnoperitoneum during laparoscopic cholecystectomy. Surg Endosc 13: 376-381.

6. Ishizaki $\mathrm{Y}$, Bandae $\mathrm{Y}$, Shimomura $\mathrm{K}$, Abe $\mathrm{H}$, Ohtomo $\mathrm{Y}$, et al. (1993) Safe intraabdominal pressure of carbon dioxide pneumoperitoneum during laparoscopic surgery. Surgery 114: 549-554.

7. Gurusamy KS, Samraj K, Davidson BR (2008) Abdominal lift for laparoscopic cholecystectomy. Cochrane database Syst Rev 16: CD006574.

8. van Zundert AA, Stultiens G, Jakimowicz JJ, Peek D, van der Ham WG, et al. (2007) Laparoscopic cholecystectomy under segmental thoracic spinal anesthesia: A feasibility study. Br J Anaesth 98: 682-686.

9. Youssef MA, saleh Al-Mulhim A (2007) Effects of different anesthetic techniques on antidiuretic hormone secretion during laparoscopic cholecystectomy. Surg Endosc 21: 1543-1548.

10. Feig BW, Berger DH, Dougherty TB, Dupuis JF, Hsi B, et al. (1994) Pharmacological intervention can reestablish baseline hemodynamic parameters during laparoscopy. Surgery 116: 733-739.

11. AM Koivusalo, M Scheinin, I Tikkanen, T Yli-Suomu, S Ristkari, et al. (1998) Effects of esmolol on hemodynamic responses to $\mathrm{CO} 2$ pneumoperitoneum for laparoscopic surgery. Acta Anaesthesiol Scand 42: 510-517.

12. Jee D, Lee D, Yun S, Lee C (2009) Magnesium sulphate attenuates arterial pressure increases during laparoscopic cholecystectomy. Br J Anaesth 103: 484-489.

13. Aho M, Scheinin M, Lehtinen AM, Erkola O, Vuorinen J, et al. (1992) Intramuscularly administered dexmedetomidine attenuates hemodynamic and stress hormone responses to gynecologic laparoscopy. Anesth Analg 75: 932-939.

14. Feld JM, Hoffman WE, Stechert MM, Hofman IW, Ananda RC (2006) Fentanyl or dexmedetomidine combined with desflurane for bariatric surgery. J Clin Anesth 18: 24-28.

15. Tufanogullari B, White PF, Peixoto MP, Kianpour D, Lacour T, et al. (2008) Dexmedetomidine infusion during laparoscopic bariatric surgery: The effect on recovery outcome variables. Anesth Analg 106: 1741-1748.

16. Bloor BC, Ward DS, Belleville JP, Maze M (1992) Effects of intravenous dexmedetomidine in humans. II. Hemodynamic changes. Anesthesiology 77: 1134-1142.

17. Grewal A (2011) Dexmedetomidine: New avenues. J Anaesthesiol Clin Pharmacol 27: 297-302.

18. Talke P, Chen R, Thomas B, Aggarwall A, Gottlieb A, et al. (2000) The hemodynamic and adrenergic effects of perioperative Dexmedetomidine infusion after vascular surgery. Anesth Analg 90: 834-839.

19. Manne GR, Upadhyay MR, Swadia VN (2014) Effects of low dose dexmedetomidine infusion on haemodynamic stress response, sedation and post-operative analgesia requirement in patients undergoing laparoscopic cholecystectomy. Indian J Anaesth 58: 726-731.

20. Bhattacharjee DP, Nayek SK, Dawn S, Bandopadhyay G, Gupta K (2010) Effects of dexmedetomidine on haemodynamics in patients undergoing laparoscopic cholecystectomy- a comparative study. J Anaesth Clin Pharmacol 26: 45-48. 